\title{
Configurações
}

Revista de sociologia

\section{Introdução: Justiça, Direito(s) e Instituições}

\section{Manuela Ivone Cunha, Sílvia Gomes e Vera Duarte}

\section{OpenEdition}

\section{Journals}

\section{Edição electrónica}

URL: http://journals.openedition.org/configuracoes/4244

DOI: $10.4000 /$ configuracoes.4244

ISSN: 2182-7419

\section{Editora}

Centro de Investigação em Ciências Sociais

\section{Edição impressa}

Paginação: 7-12

ISSN: 1646-5075

\section{Refêrencia eletrónica}

Manuela Ivone Cunha, Sílvia Gomes e Vera Duarte, «Introdução: Justiça, Direito(s) e Instituições », Configurações [Online], 20 | 2017, posto online no dia 28 dezembro 2017, consultado o 30 abril 2019. URL : http://journals.openedition.org/configuracoes/4244; DOI : 10.4000/configuracoes.4244 
Introdução - Justiça, direito(s) e instituições. Configurações, vol. 20, 2017, pp. 7-12.

\title{
Introdução Justiça, direito(s) e instituições
}

\author{
MANUELA IVONE CUNHA \\ CRIA -Universidade do Minho \\ SÍLVIA GOMES \\ CICS.NOVA.UMinho e ISMAI \\ VERA DUARTE \\ ISMAI e CICS.NOVA. UMinho
}

A publicação deste volume, desdobrada em dois números da revista Configurações, tem origem num duplo evento, organizado conjuntamente: o Segundo Encontro da Secção Temática "Sociologia do Direito e da Justiça" da Associação Portuguesa de Sociologia (STSDJ) e as V Jornadas do Mestrado em Crime, Diferença e Desigualdades da Universidade do Minho ${ }^{1}$.

As preocupações de abrangência e de pertinência que orientaram o seu formato de origem coincidiram com as que presidiram ao anterior encontro da STSDJ: procurava-se proporcionar o cruzamento de um espetro largo de trabalhos de natureza sociojurídica, em diferentes domínios de investigação, em torno de uma dimensão na realidade social que tivesse adquirido uma relevância específica reconhecível na atualidade. Para mais, o tema "Justiça, Direito(s) e Instituições", agora convidando sobretudo a pensar os dois primeiros termos - justiça e direito/s -- no quadro do último - as instituições -, prestar-se-ia a ser trabalhado na continuidade ou em complementaridade com o tema desse mesmo primeiro encontro, intitulado "Direitos, Justiça, Cidadania. O direito na constituição da política”.

1 Realizado na Universidade do Minho em 27 e 28 de Janeiro 2017, o encontro reuniu cerca de cem investigadoras/es e contou com uma organização interinstitucional, envolvendo o Centro Interdisciplinar de Ciências Sociais (CICS.NOVA.UMinho), as Escolas de Direito e de Psicologia da UMinho, o Centro em Rede de Investigação em Antropologia (CRIA-UMinho), o Centro de Investigação Interdisciplinar em Direitos Humanos (CIIDH) e a Unidade de Investigação em Criminologia e Ciências do Comportamento do ISMAI (UICCC.ISMAI). Agradece-se aos participantes que se dispuseram a submeter a sua apresentação sob a forma de artigo, bem como aos que entretanto se juntaram a este volume de contribuições. 
Como então justamente argumentou Pierre Guibentif (2017: 7-8), a investigação em sociologia do direito e da justiça tem dado prioridade aos contextos da produção (originária ou derivada) do direito, e a contextos de invocação de regras jurídicas, ou seja, a "lugares e momentos nos quais as questões jurídicas passam para o primeiro plano" (ibidem). Tratou-se então de focar, além disso, outros contextos em que o direito desempenha também um papel importante, mesmo se em segundo plano. É o caso da política, quaisquer que sejam os âmbitos ou sujeitos coletivos considerados na ação política, estatais ou não estatais - no sistema político, na administração pública, nas políticas públicas, na cidadania, na criação de direitos e de exclusões.

O encontro "Justiça, Direito(s) e Instituições", que se lhe seguiu, pretendeu por sua vez colocar a tónica no contexto das instituições, mais propriamente nas possíveis modulações específicas que estas produzem ou induzem, e cuja importância tem vindo a merecer uma atenção crescente a vários títulos. Ocupando um lugar charneira entre a ordem das interações individuais e a das estruturas sociais, é também nelas que ocorrem aquilo a que Goffman (1983) se referiu como "encontros de processamento de pessoas", encontros esses suscetíveis de acentuar ou, pelo contrário, de atenuar linhas estruturais preexistentes. Dado que as prescrições formais nunca determinam nem regulam completamente o modo como os agentes investidos de poderes institucionais desempenham os seus papéis, há margem para negociações e interpretações situacionais (Lagroye, Offerlé 2010) que em parte dependem da maneira como as interações têm lugar nesses contextos, e cujas repercussões podem ser decisivas na vida das pessoas circunstancialmente aí "processada”.

É nas instituições, no seu funcionamento quotidiano, que se capta a justiça em ação; é também nelas que são concedidos ou negados direitos; que políticas e orientações são variavelmente implementadas; que sanções, tratamentos e leis são interpretados. Em suma, é nas instituições que leis, sanções, políticas e orientações são, afinal, coproduzidas na atividade concreta e situada dos seus agentes, na relação com os respetivos públicos.

Se a pertinência de um enfoque nas instituições pode ser defendida em termos genéricos, quisemos porém destacar, como sugerimos atrás, a relevância específica de que ele se reveste na atualidade, em condições também elas específicas. Entendemos essa relevância nos moldes avançados por Vincent Dubois, um dos convidados do Encontro, que a argumenta não a partir de uma noção abstrata e universal de instituições, mas a encara desde logo como uma questão empírica. A saber: "sob que condições socio-históricas podem as instituições (de que tipo, tratando de que tipo de população e de que tipo de problemas), funcionar como intermediárias entre a ordem da interação e a ordem social?” (2014a: 65). Precise-se que as instituições são aqui encaradas simultaneamente como instâncias que incorporam e garantem normas sociais, e como locais onde as interações ocorrem concretamente. 
Como a própria investigação deste autor tem apontado (Dubois 2014b, 2014a; ver ainda, na mesma linha, Fassin 2013), em razão da crise económica e social, e em aparente contradição com a suposta retração do Estado, as instituições públicas (mas também as que desempenham funções "terceirizadas") têm-se tornado mais influentes, não menos, na vida de certos grupos, e em particular de populações vulneráveis e frações precarizadas. Em parte tal prende-se com um deslocamento genérico de políticas baseadas em direitos (de natureza relativamente estável e previsível) para outras condicionadas à avaliação individual (de natureza mais incerta, imprevisível e à mercê dos juízos de outrem).

Este contexto, mais orientado para a individualização e para a responsabilização, altera a importância e o sentido das interações que têm lugar nas instituições. Aliás, com base nessas interações podem ser tomadas decisões de peso, com grande impacto numa vida, daí o seu poder estratégico no governo das condutas. É por esta razão que é salientada a emergência de uma governamentalidade assente em interações face-a-face. É até bem possível que a burocratização e formalização de procedimentos, que afeta todo o tipo de organizações, se acompanhe em muitos casos, paradoxalmente, de uma maior margem de manobra dos "burocratas de rua" (Dubois 2014a. Lipsky 1980), inclusive quando assumem posições “juridistas”, ou de rigorismo jurídico. $\mathrm{Na}$ conferência plenária que proferiu, o próprio V. Dubois mostrou como a monitorização dos beneficiários de prestações sociais por ele estudada em França, monitorização essa declaradamente regida por objetivos de luta contra a fraude e de sanção dos pobres "não merecedores", ilustra bem os novos usos sociais das nomas legais nas instituições que a levam a cabo, bem como um processo de judiciarização que ecoa a 'criminalização da pobreza' observada em vários contextos (Wacquant 2009).

A gramática das novas formas de governamentalidade, em que se conjugam ideias de responsabilidade individual, avaliação de risco e monitorização casuística, atravessa tanto a gestão social como a gestão penal de problemas sociais. No caso da gestão penal, encontramo-la em diferentes etapas e momentos de ação dos dispositivos de controlo do crime: tanto no âmbito da sentença ${ }^{2}$ e do pós-sentença, como no da prevenção - mais propriamente na "nova prevenção”, cuja lógica mais imediatista, centrada na gestão situacional do risco, a diferencia da prevenção clássica. De resto, impõe-se aludir aqui ao trabalho recente de Fabienne Brion, outra convidada do Encontro, que caracterizou por seu turno alguns dos avatares mais recentes desta governamentalidade tal como se dão a ver na implementação prática, por diversas instituições, das políticas de contra-radicalização e des-radicalização na Bélgica, desenvolvidas como medidas de prevenção do terrorismo. Além da disseminação da desconfiança 
que produzem, F. Brion analisa o modo como, nesta formação emergente no campo penal, a suspeita se torna em nova técnica de governo e se opera uma passagem de formas de "governo através do crime" (Simon 2007) para formas de "governo através da suspeição” (ver também Guittet e Brion 2017).

Em vários âmbitos e por diversas vias, portanto, novas governamentalidades ampliaram o papel das instituições e dos seus atores, bem como a importância dos encontros que nelas têm lugar. Foi nesse sentido que convidámos à apresentação de propostas que contribuíssem para esclarecer o papel presente das instituições no governo das condutas numa variedade ampla de campos, do social ao jurídico. 3

Os textos reunidos na primeira parte deste volume, de proveniência multidisciplinar, centram-se sobretudo em instituições e agentes institucionais do sistema de justiça.

O artigo de Maria João Leote de Carvalho promove uma discussão sobre as origens da justiça juvenil nas sociedades ocidentais, fazendo uma análise sobre o modo como a relação entre justiça, direitos e instituições enforma os diplomas legais e as práticas da justiça juvenil em Portugal. Mais especificamente, analisa como do passado, centrado no 'menor', se evoluiu para a justiça 'amiga' das crianças no presente. Diz a autora que nenhum princípio de justiça ancorado no Direito das Crianças e dos Jovens é, por si mesmo, absoluto quando transposto para a prática judiciária.

Ana Manso e Luis Fernandes, por sua vez, mostram como os discursos dos sujeitos internados são enformados pelas instituições, isto é, como as narrativas produzidas pelos jovens em internamento em centro educativos são determinadas, na sua verdade ou falsidade, pelo próprio dispositivo de intervenção tutelar e pelo discurso que o legitima. O artigo evidencia como a subjetivação dos jovens institucionalizados tende a encenar o sistema de verdade que, se por um lado sustenta o próprio dispositivo de intervenção tutelar, também assume um carácter estratégico em termos da sobrevivência institucional do jovem.

A partir de reflexões teóricas entre crime de colarinho branco, prisão e ressocialização, o artigo de Carlos Fernández Abad mostra-nos as desarticulações existentes entre a (finalidade da) justiça e as suas instituições. O autor problematiza sobre a finalidade da pena de prisão para indivíduos condenados por crimes de colarinho branco, quando tradicionalmente aquelas instituições estão pensadas e trabalham primordialmente no sentido da ressocialização de populações excluídas e desfavorecidas. Ao mostrar que a prisão não ressocializa este grupo social, defende portanto a formulação de categorias aplicáveis a todas as formas delitivas, o que implica romper com associações simplistas

3 Tratou-se de um convite aberto, somado ao que resultou das propostas apresentadas nas dezasseis sessões temáticas do Encontro. Estas organizaram-se em torno dos temas Justiça, liberdade e sociedade; Instituições prisionais e percursos (pós)prisionais; Género, violência de género e instituições. Foram ainda discutidas Questões emergentes, evoluções recentes e desafios. 
entre crime e exclusão social, assim como questionar a estrutura social atual e as suas relações de poder.

Debruçando-se sobre o chamado setor sociocultural nas instituições prisionais, Daniel Maciel e Manuela Ivone Cunha mostram como a dinamização deste setor é atualmente uma parte integrante da gestão das prisões portuguesas. Incentivados a participar ativamente nos "espaços suspensos" e "tempos intersticiais" em que se organizam atividades lúdicas e artísticas, nas quais mobilizam as competências próprias que tenham neste âmbito, os reclusos beneficiam de algum alívio na pressão disciplinar da prisão e de uma relação próxima com os técnicos, ao mesmo tempo que se tornam "prata da casa" e imagem pública da prisão. A análise desta posição ambígua entronca numa reflexão sobre uma modalidade penal em que os reclusos assumem parte da administração da sua própria pena.

O texto de Claúdia Resende incide sobre os quotidianos de jovens estrangeiros a cumprir pena de prisão efetiva em contexto português. A partir de uma abordagem etnográfica e de relatos na primeira pessoa, mostra como os usos da língua materna de falantes de crioulo de cidadãos de nacionalidade cabo-verdiana e guineense no meio prisional se apresenta como elemento indissociável do lazer e como estratégia de "sobrevivência institucional".

Ainda no âmbito das instituições prisionais, e abarcando dinâmicas extramuros na órbita destas instituições, Ana Pereira Roseira propõe uma análise transversal do estigma na vida dos guardas prisionais, seguindo um percurso em que este é transportado de dentro para fora, da esfera do trabalho para a esfera familiar, num efeito de contaminação da intimidade.

Por fim, centrando-se em profissionais de um outro domínio nas instituições de justiça, o artigo de Sandra Sousa e Luís Neves discute o estatuto profissional e a natureza do papel do Agente de Execução, um operador importante numa perspetiva de “justiça em ação". A partir de um enquadramento jurídico-legal, os autores defendem que a atividade do Agente de Execução, enquanto forma de intervenção judiciária, deve ser detentora de uma função dotada de uma atribuição legal para o exercício de poderes públicos de relevância social, e deve ser entendida enquanto forma de intervenção tanto judiciária como social.

\section{Referências bibliográficas}

CUNHA, Manuela Ivone (2014), “The ethnography of prisons and penal confinement”, Annual Review of Anthropology, 43 (1), 217-33.

DUBOIS, Vincent (2014a), “Ordem institucional, ordem interaccional e ordem social: administrando o bem-estar, disciplinando os pobres”, Cadernos de Ciências Sociais, 27(2), 53-66.

DUBOIS, Vincent (2014b), “The State, Legal Rigor and the Poor: The Daily Practice of Welfare Control”, Social Analysis, 58(3), 38-55.

FASSIN, Dider, Yasmine, Isabelle Coutant, Jean-Sébastien Eideliman, Fabrice Fernandez, Nicolas Fischer, Carolina Kobelinsky, Chowra Makaremi, Sarah Mazouz, Sébastien Roux (2013), Juger, réprimer, accompagner. Essai sur la morale de l’État, Paris, Seuil. 
GOFFMAN, Erving (1983), “The interaction order”, American Sociological Review, 48 (1), 1-17. GUIBENTIF, Pierre (2017), "Direitos, Justiça, Cidadania. O direito na constituição da política", in A. C. Ferreira, M. J. Leote de Carvalho, P. Guibentif, S. Gomes, V. Duarte, A. Santos, P. Casaleiro (Orgs.), Direitos, Justiça, Cidadania. O direito na constituição da política. Atas do Primeiro Encontro da Secção Temática "Sociologia do Direito e da Justiça” da Associação Portuguesa de Sociologia, CesContextos, n 19, 7-36.

GUITTET, Emanuelle-Pierre e Fabienne Brion (2017), “The New Age of Suspicion”, in E. Ekhlund, A. Zevnik and E.-P. Guittet, Politics of Anxiety, London/New York, Rowman \& Littlefield, 79-99.

LAGROYE, Jacques e Michel Offerlé (Org.) (2011), Sociologie de l'institution, Paris, Belin.

LIPSKY, Michael (1980), Street-Level Bureaucracy: Dilemmas of the Individual in Public Services. New York, Russel Sage Foundation.

SIMON, J. (2007), Governing Through Crime. New York, New York University Press

WACQUANT, Loï (2009), Punishing the Poor, Duke University Press.

GUITTET, Emanuelle-Pierre e Fabienne Brion (2017), "The New Age of Suspicion”, in E. Ehlund, A. Zevnik and E.-P. Guittet, Politics of Anxiety, London/New York, Rowman \& Littlefield, 79-99.

LAGROYE, Jacques e Michel Offerlé (Org.) (2011), Sociologie de l'institution, Paris, Belin.

LIPSKY, Michael (1980), Street-Level Bureaucracy: Dilemmas of the Individual in Public Services. New York, Russel Sage Foundation.

SIMON, J. (2007), Governing Through Crime. New York, New York University Press.

WACQUANT, Loï (2009), Punishing the Poor, Duke University Press. 